\title{
A Reconstruction of Development of the Periodic Table Based on History and Philosophy of Science and Its Implications for General Chemistry Textbooks
}

\author{
Angmary Brito, ${ }^{1}$ María A. Rodríguez, ${ }^{2}$ Mansoor Niaz ${ }^{2}$ \\ ${ }^{1}$ Instituto Universitario de Tecnología “José Antonio Anzoátegui,” El Tigre, \\ Estado Anzoátegui, Venezuela \\ ${ }^{2}$ Epistemology of Science Group, Department of Chemistry, Universidad de Oriente, \\ Apartado Postal 90, Cumaná, Estado Sucre 6101A, Venezuela
}

Received 28 July 2003; Accepted 12 May 2004

\begin{abstract}
The objectives of this study are: (a) elaboration of a history and philosophy of science (HPS) framework based on a reconstruction of the development of the periodic table; (b) formulation of seven criteria based on the framework; and (c) evaluation of 57 freshman college-level general chemistry textbooks with respect to the presentation of the periodic table. The historical reconstruction of the periodic table showed that the periodicity of the elements could be construed as an inductive generalization or as a function of the atomic theory. There is considerable controversy with respect to the nature of Mendeleev's contribution, and various alternatives are discussed: ordered domain; empirical law; and a theory with limited explanatory power. Accommodation of the elements according to their physicochemical properties is considered to be the major contribution of the periodic table by all textbooks, followed by contrapredictions of previously unknown elements (30 textbooks), and novel predictions (corrections of atomic mass) of known elements (10 textbooks). The relative importance of accommodation and prediction within an HPS framework is generally ignored. Few textbooks have attempted to explore the possible cause of periodicity in the table and very few textbooks have explored the nature of Mendeleev's contribution. The development of the periodic table as a sequence of heuristic principles in the form of a convincing argument has been ignored. The textbook approach of emphasizing that the development of the periodic table was an inductive generalization, and that Mendeleev had no model or theory, does not facilitate the spirit of critical inquiry that led the scientists to grapple with alternative interpretations, conflicts, and controversies. It is concluded that the development of the periodic table went through a continual critical appraisal (conflict and controversy), in which scientists presented various tentative theoretical ideas to understand the observed phenomena. (c) 2004 Wiley Periodicals, Inc. J Res Sci Teach 42: 84-111, 2005
\end{abstract}

\footnotetext{
Contract grant sponsor: Consejo de Investigación, Universidad de Oriente, Venezuela. Correspondence to: M. Niaz; E-mail: niazma@cantv.net or mniaz@sucre.udo.edu.ve DOI 10.1002/tea.20044

Published online 30 November 2004 in Wiley InterScience (www.interscience.wiley.com).
} 
Most chemistry teachers consider the periodic table to be an important concept, both in principle and practice. It facilitates a succinct organization and understanding of the fundamental building blocks of chemistry, the chemical elements (Atkins, 1995). Research in chemistry education continues to emphasize the importance of the periodic table for learning chemistry (Akeroyd, 1991; Ben-Zvi \& Genut, 1998; Bouma, 1989; Campbell, 1989; Giunta, 1998; Goh \& Chia, 1989; Laing, 1989; Marshall, 2000; Rayner-Canham, 2000; Robinson, 2000; Scerri, 1998; Schmidt, Baumgärtner, \& Eybe, 2003; Treptow, 1994). According to one historian of chemistry: "From the 1870s Mendeleev's Periodic Table came to adorn every chemical lecture room; it compressed a great deal of knowledge into a small compass, meaning that the student no longer had to be burdened with a great load of unrelated brute facts" (Knight, 1998, p. xii). Another historian goes beyond by recognizing that the periodic table, " . . . has contributed much more than mere classification. It has been a conceptual tool which has predicted new elements, predicted unrecognized relationships, served as a corrective device, and fulfilled a unique role as a memory and organization device" (Ihde, 1969, p. ix). Mendeleev's periodic table formed part of his textbook (Principles of Chemistry, first written between 1868 and 1870), in which he endeavored to facilitate students' understanding of methods of observation, experimental facts, laws of chemistry, and the "... unchangeable substratum underlying the varying forms of matter" (author's preface to the sixth Russian edition, reproduced in Mendeleev [1897], p. vii). Mendeleev's textbook went through eight editions (Russian) in his lifetime and five more after his death. In spite of the long history of the periodic table and its relevance for chemistry and chemistry education, historians and philosophers of science are still trying to understand its origin, nature, and development (Bensaude-Vincent, 1986; Brush, 1996; Scerri \& Worrall, 2001).

\section{Purpose}

The objectives of this study include: (a) elaboration of a history and philosophy of science framework based on a reconstruction of the development of the periodic table; (b) formulation of criteria based on the framework that could be useful in the evaluation of general chemistry textbooks; and (c) evaluation of freshman college-level general chemistry textbooks with respect to the presentation of the periodic table.

\section{A History and Philosophy of Science Framework}

\section{Development of Early Periodic Systems}

Döbereiner is generally credited to have presented the first periodic system in 1817, by illustrating how in a triad, such as calcium, strontium, and barium, the atomic weight of strontium was an average of calcium and barium. van Spronsen (1969) presents a detailed account of various other attempts to classify elements between 1817 and 1860. However, a major problem with such classifications was that the atomic weights were not yet determined correctly and nor were they well understood, because “... Dalton's atomic theory was too recent to have been conclusively demonstrated, ..." (van Spronsen, 1969, p. 95). In 1817, Dobereiner had only six correct atomic weights available.

\section{Role of the Karlsruhe Congress of 1860}

Most historians consider the international congress held in Karlsruhe (September 3-5, 1860) as crucial in the development of chemistry. A circular (dated July 10, 1860) sent by the organizers of the congress to most outstanding chemists of Europe outlined its objective as the need to reach a 
consensus on "More precise definitions of the concepts of atom, molecule, equivalent, atomicity, alkalinity, etc.; discussion on the true equivalents of bodies and their formulas; initiation of a plan for a rational nomenclature" (reproduced in de Milt, 1951, p. 421). Mendeleev (then 26 years of age) attended the congress and was greatly impressed by Cannizaro's contribution and, in a letter dated September 7, 1860, summarized an important achievement of the congress:

It is decided to take a different understanding of molecules and atoms, considering as a molecule the amount of a substance entering a reaction and determining physical properties, and considering as an atom the smallest amount of a substance included in a molecule. Further, it reached an understanding about equivalents, considered as empirical, not depending on the understanding about atoms and molecules. (reproduced in de Milt, 1951, p. 422)

\section{Discoverers of the Periodic Table}

According to van Spronsen (1969) the following can be considered to be independent discoverers of the periodic table:

a) De Chancourtois presented his periodic table based on a helical graphic system in 1862. He was the first to recognize that properties of the elements are a function of their atomic weight.

b) Odling arranged 57 elements in the order of increasing atomic weights in 1864 . He also presented a paper at the Karlsruhe congress.

c) Meyer also attended the Karlsruhe congress and in 1864 presented the first of a series of periodic tables as part of a textbook. Meyer based his table on Dalton's atomic theory, Avogadro's hypothesis, and, "... unlike Mendeleev always kept in mind the possible existence of a primary substance underlying the composition of elements" (van Spronsen, 1969, p. 131).

d) Newlands presented his law of octaves in 1865, according to which properties of the elements repeated after each series of seven elements. Most textbooks mention it.

e) Hinrichs presented a periodic relationship of the elements based on shape of the atoms (obtained from spectral data) in 1866.

f) Mendeleev discovered the periodic system on February 17, 1869 and was published in Russian in the same year, followed by an abstract in German (Mendeleev, 1869).

\section{Role of Accommodation and Prediction in Development of the Periodic Table}

Mendeleev (1869) enunciated the first form of his periodic law and later elaborated in the following terms: "The properties of simple bodies, the constitution of their compounds, as well as the properties of these last, are periodic functions of the atomic weights of elements" (Mendeleev, 1879 , p. 267). It is important to note that the elucidation of the concept of atomic weight by Stanislao Cannizaro at Karlsruhe was crucial in the discovery of the periodic law. Interestingly, three of the discoverers attended the congress. According to van Spronsen (1959), elaboration of the periodic table was difficult and took a long time due to "... lack of a definite conception of atomic weight, which is very closely connected with the definitions of molecules and atoms" (p. 565). Availability of the atomic weights of about 60 elements enabled Mendeleev to accommodate the elements in the table according to various physicochemical properties (density, specific heat, atomic weight, atomic volume, melting point, valence, oxides, chlorides, and sulfides). In contrast to other discoverers, Mendeleev's work was characterized by the following aspects: "...the division into main and sub-groups, the vacant spaces left for undiscovered elements together with the prediction of some of their properties, i.e., the homologues of 
aluminium and silicon ..., the classification of the transition metals, and the reversal of telluriumiodine" (van Spronsen, 1969, pp. 134-135). Historians and philosophers of science continue to debate as to what was crucial for the acceptance of the periodic law by the scientific community: accommodation of the existing elements or the prediction of new ones (Akeroyd, 2003; Brush, 1996; Kaji, 2003; Lipton, 1991; Maher, 1988; Scerri \& Worrall, 2001). Lipton (1991) and Maher (1988) favor a predictivist thesis, viz., Mendeleev's law was accorded a greater recognition after the discovery of the first predicted element (gallium) in 1875. Scerri and Worrall (2001), on the other hand, suggest that accommodations were more important. Brush (1996) seems to follow an intermediate position between the two extremes.

Mendeleev left various vacant spaces in his table and made many predictions and, of these, the following are the most important:

a) Eka-aluminum (atomic weight $=68$, density $=6.0$, atomic volume $=11.5$ ). This was discovered by the French chemist Paul Émile Lecoq de Boisbaudran in 1875, and was named gallium.

b) Eka-boron (atomic weight $=44$, density $=3.5$ ). This was discovered by the Swedish chemist Lars-Frederik Nilson in 1879 , and was named scandium.

c) Eka-silicon (atomic weight $=72$, density $=5.5$, atomic volume $=13$ ). This was discovered by the German chemist Clemens Alexander Winkler in 1886, and was named germanium.

Besides the atomic weights and physical properties (just presented), some of the chemical properties (formation of oxides, chlorides) of the predicted elements coincided to a remarkable degree with the discovered elements. According to van Spronsen (1969), after the discovery of gallium in 1875, “... Mendeleev rightly concluded that the validity of the periodic system of elements could no longer be questioned. The confirmation of this prediction may certainly be called the culminating point in the history of the periodic system" (p. 221). This precisely is the point of contention among philosophers of science, viz., what made Mendeleev's periodic law valid-accommodations dating from 1869 or the predictions from 1875 onwards.

According to Brush (1996), scientists generally propose a hypothesis, deduce its consequences, make predictions, and do experiments to see if the predictions are borne out. Ziman (1978) believes that the "... fundamental purpose of science is to acquire the means for reliable prediction" (p. 32). Actual scientific practice, however, is much more complex and controversial. To facilitate understanding, Brush suggests the following types of predictions: (a) Contraprediction: foretelling the existence of unknown elements and their properties. Brush explicitly points out that the discovery of gallium was a contraprediction. (b) Novel prediction: correction of some of the existing atomic weights by Mendeleev (e.g., beryllium changed from 14 to 9 , uranium changed from 120 to 240, tellurium changed from 128 to 125). (c) Retrodiction: explanation of a fact known before the theory was proposed. Although, according to Brush, the convincing power increases in the following order: retrodiction, novel prediction, and contraprediction, there is no consensus among philosophers on this issue. According to Scerri and Worrall (2001), "We argue in particular that certain 'accommodations' within Mendeleev's table were at least as significant as any predictive success - notably the accommodation of argon, the first of the 'noble gases' to be identified" (p. 411).

\section{Difficulties Associated With Accommodation of Argon in the Periodic Table}

Discovery of an inert gas (later named argon) was announced at a meeting of the Royal Society by Rayleigh and Ramsey on January 31, 1895. This discovery led to an intense debate as to 
the nature of the gas and its place in the periodic table, and was ultimately a crucial test for Mendeleev's periodic law. Ramsey (1897) recalled the events at a meeting of the British Association in the following terms:

The discovery of argon at once raised the curiosity of Lord Rayleigh and myself as to its position in this table [Mendeleev's]. With a density of nearly 20, if a diatomic gas, like oxygen and nitrogen it would follow fluorine in the periodic table... But when the ratio of its specific heats $\left[\mathrm{C}_{\mathrm{p}} / \mathrm{C}_{\mathrm{v}}\right]$ had, ... unmistakably shown that it was molecularly monoatomic, and not diatomic, as at first conjectured, it was necessary to believe that its atomic weight was 40 , and not 20 , and that it followed chlorine in the periodic table, and not fluorine. But here arises a difficulty. The atomic weight of chlorine is 35.5 , and that of potassium, the next element in order in the table, is 39.1; and that of argon, 40, follows, and does not precede, that of potassium, as it might be expected to do. (p. 379)

This clearly shows how the placing of an element was not a straightforward question of ordering the elements in the ascending order of their atomic weights. These difficulties led some chemists, including Rucker (President of the Royal Society), to entertain the possibility of rejecting the periodic table (cf. Rucker \& Kelvin, 1895, p. 62). Mendeleev even suggested that argon could have been tri-atomic nitrogen, $\mathrm{N}_{3}$, and later was convinced by Ramsey, at a meeting in Berlin, to place argon into a separate group (Scerri \& Worrall, 2001, pp. 444-445). The placement of argon was finally solved by placing argon and the other noble gases in a new group between the halogens and the alkali metals (Ramsey \& Travers, 1901). Mendeleev considered the accommodation of argon as a glorious confirmation of the general applicability and validity of the periodic law (Smith, 1975, p. 460). According to Scerri and Worrall (2001), “.... this accommodation of argon within Mendeleev's scheme was a major feather in its cap-no less major than any other empirical success, whether predictive in the temporally novel sense or not" (p. 445).

\section{Periodicity in the Periodic Table as a Function of the Atomic Theory}

According to van Spronsen (1969):

The actual development of the periodic system seemed to require a catalyst! We think it proper to attribute this catalytic action to Cannizaro's famous Karlsruhe lecture at the 1860 Congress. He made the distinction between atoms and molecules and defined such concepts as valence; ... this initiated the second stage of the discovery and started the history proper of the periodic system of chemical elements. (p. 1, emphasis added)

In spite of this fairly categorical statement with respect to the role played by the atomic theory by a major historian of the periodic table, it is still possible to observe that some historians and textbooks in general attribute the success primarily to empirically observed properties of the elements (inductive generalization). Many chemistry students must have wondered as to how Mendeleev and the other co-discoverers could have conceptualized the underlying theoretical rationale of the elements that manifested itself in periodicity. It is important to recall that most of the pioneering work of Mendeleev was conducted from 1869 to 1889, before Thomson (1897), Rutherford (1911), Bohr (1913), and Moseley (1913) laid the foundations of the modern atomic theory. So how could Mendeleev conceptualize periodicity as a function of the atomic theory? An answer to this question will precisely show Mendeleev's ingenuity, far-sightedness, creativity, and the ability to "speculate." Despite Mendeleev's own ambivalence and ambiguity, a historical reconstruction does provide a convincing story of this remarkable contribution to our knowledge. 
Before presenting the reconstruction it is important to note that Mendeleev had the following important sources of information: Dalton's atomic theory; law of multiple proportions; Cannizaro's Karlsruhe lecture; fairly reliable atomic weights; atomicity (valence); and various physical and chemical properties of the elements.

Stage 1. In his first publication, Mendeleev referred to the relationship, albeit implicitly, between periodicity, atomic weights, and valence: "The arrangement according to atomic weight corresponds to the valence of the element and to a certain extent the difference in chemical behavior, for example Li, Be, B, C, N, O, F.” (Mendeleev, 1869, p. 405, original italics).

Stage 2. After the discovery of gallium and scandium, Mendeleev expressed the relationship between atomic weight and atomic theory much more explicitly:

It is by studying them [atomic and molecular weights], more than by any other means, that we can conceive the idea of an atom and of a molecule. By this fact alone we are enabled to perceive the great influence that studies carried on in this direction can exercise on the progress of chemistry .... The expression atomic weight* implies, it is true, the hypothesis of the atomic structure of bodies. (Mendeleev, 1879, p. 243, emphasis added)

The asterisk leads the reader to the following footnote: "By replacing the expression of atomic weight by that of elementary weight, I think we should, in the case of elements, avoid the conception of atoms." The footnote shows Mendeleev's ambiguity/ambivalence toward the atomic theory and will be dealt with later (see Stage 6).

Stage 3. Another example of Mendeleev's ambivalence can be observed from the following: "I shall not form any hypotheses, either here or further on, to explain the nature of the periodic law; for, first of all, the law itself is too simple*..." (Mendeleev, 1879, p. 292). The asterisk leads the reader to the following footnote: "However, I do not ignore that to completely understand a subject we should possess, independently of observations [and experiences] and of laws [as well as systems], the meanings of both one and the other."

Stage 4. Although Mendeleev stated in 1879 that he would not formulate an hypothesis, 10 years later in his famous Faraday lecture, Mendeleev (1889) not only attributed the success of the periodic law to Cannizaro's ideas on the atomic theory (pp. 636-637) but went on to explicitly formulate the following hypothesis: " ... the veil which conceals the true conception of mass, it nevertheless indicated that the explanation of that conception must be searched for in the masses of atoms; the more so, as all masses are nothing but aggregations, or additions, of chemical atoms..." (p. 640, emphasis added).

Stage 5. Again, at the Faraday lecture, Mendeleev (1889) took extreme care to explain the periodicity of properties of chemical elements on the basis of atomic theory. We cite at length:

The periodic law has shown that our chemical individuals [atoms] display a harmonic periodicity of properties, dependent on their masses.... An example will better illustrate this view. The atomic weights-

$\mathrm{Ag}=108 \quad \mathrm{Cd}=112 \quad \mathrm{In}=113 \quad \mathrm{Sn}=118 \quad \mathrm{Sb}=120 \quad \mathrm{Te}=125 \quad \mathrm{I}=127$

steadily increase, and their increase is accompanied by a modification of many properties which constitutes the essence of the periodic law. Thus, for example, the densities of the above elements decrease steadily, being respectively-

$\begin{array}{lllllll}10.5 & 8.6 & 7.4 & 7.2 & 6.7 & 6.4 & 4.9\end{array}$ 
while their oxides contain an increasing quantity of oxygen-

$\begin{array}{lllllll}\mathrm{Ag}_{2} \mathrm{O} & \mathrm{Cd}_{2} \mathrm{O}_{2} & \mathrm{In}_{2} \mathrm{O}_{3} & \mathrm{Sn}_{2} \mathrm{O}_{4} & \mathrm{Sb}_{2} \mathrm{O}_{5} & \mathrm{Te}_{2} \mathrm{O}_{6} & \mathrm{I}_{2} \mathrm{O}_{7}\end{array}$

But to connect by a curve the summits of the ordinates expressing any of these properties would involve the rejection of Dalton's law of multiple proportions. Not only are there no intermediate elements between silver, which gives $\mathrm{AgCl}$, and cadmium which gives $\mathrm{CdCl}_{2}$, but, according to the very essence of the periodic law there can be none; in fact a uniform curve would be inapplicable in such a case, as it would lead us to expect elements possessed of special properties at any point of the curve. (pp. 640-641)

This is a clear acknowledgment of the role played by the atomic theory to explain periodicity in the periodic table. Mendeleev clearly conceptualized the relationship between the discontinuous function of the periodic properties and its dependence on the law of multiple proportions, which in the ultimate analysis meant atomic theory. To support our claim we once again quote from Mendeleev's Faraday lecture:

... the periodic law has clearly shown that the masses of the atoms increase abruptly, by steps, which are clearly connected in some way with Dalton's law of multiple proportions; ... While connecting by new bonds the theory of the chemical elements with Dalton's theory of multiple proportions, or atomic structure of bodies, the periodic law opened for natural philosophy a new and wide field for speculation. (Mendeleev, 1889, p. 642, emphasis added)

Interestingly, Mendeleev even seems to be considering the law of multiple proportions synonymous with Dalton's atomic theory.

Stage 6. At this stage we to refer to Mendeleev's ambiguity/ambivalence toward the atomic theory. Throughout the 19th century, positivism was the dominant philosophy, which led all scientific work to be based strictly on experimental observations and all hypothetical propositions were considered speculative and hence nonscientific (Brush, 1976; Gavroglu, 2000; Holton, 1992). Mendeleev was clearly aware of this and on many occasions went out of his way to emphasize that the periodic "... law itself was a legitimate induction from the verified facts" (Mendeleev, 1889, p. 639). In the Faraday lecture, Mendeleev emphasized the inductive aspect of the periodic law in the light of the anti-atomist Marcellin Berthelot's (1827-1907) criticism, “. . . the illustrious Berthelot, in his work Les origins de l' Alchimie, 1885, 313, has simply mixed up the fundamental idea of the law of periodicity with the ideas of Prout, the alchemists, and Democritus about primary matter. But the periodic law, based as it is on the solid and wholesome ground of experimental research, has been evolved independently of any conception as to the nature of the elements;..." (Mendeleev, 1889, p. 644). Apparently, Mendeleev's dilemma was that, on the one hand, he could rightly claim that the periodic law was based on experimental properties of the elements (an aspiration of scientists in the late 19th century), and yet he could not give up the bigger challenge, viz., the possible causes of periodicity, and hence importance of atomic theory. Rutherford (1915, p. 176) described in eloquent terms the positivist intellectual milieu of the late 19 th century.

\section{Periodicity in the Periodic Table: Contributions of Thomson, Lewis, Bohr, and Moseley}

Thomson (1897), in his celebrated article, had already suggested a possible explanation of the periodic law and later gave a detailed explanation of how properties of the elements in a period 
varied with respect to the number of corpuscles (electrons): "The gradual change in the properties of the elements which takes place as we travel along one of the horizontal rows in Mendeléefs arrangement of the elements, is also illustrated by the properties possessed by these groups of corpuscles" (Thomson, 1904, p. 259).

Lewis in an unpublished memorandum dated 1902 (reproduced in Lewis, 1923) presented a theory of the cubic atom:

In the year 1902 (while I was attempting to explain to an elementary class in chemistry some of the ideas involved in the periodic law) becoming interested in the new theory of the electron [Thomson's discovery of the electron in 1897], and combining this idea with those which are implied in the periodic classification, I formed an idea of the inner structure of the atom [model of the cubic atom] which, although it contained crudities, I have ever since regarded as representing essentially the arrangement of the electrons in the atom (Lewis, 1923, pp. 29-30, emphasis added).

In Lewis's model of the cubic atom, a cube reaches its maximum capacity of eight electrons with the last element of the period (noble gas), and then this cube becomes, in some sense, the kernel around which the larger cube of the next period is built. Lewis thought that his model could explain well the formation of polar bonds but not those in the hydrocarbons.

\begin{abstract}
Bohr (1913) in his first major publication (the trilogy) tried to establish a relationship between electron configuration and periodicity of the elements: In these considerations [electron configurations] we shall assume that the number of electrons in the atom is equal to the number which indicates the position of the corresponding element in the series of elements arranged in order of increasing atomic weight. Exceptions to this rule will be supposed to occur only at such places in the series where deviation from the periodic law of the chemical properties of the elements are observed. (Bohr, 1913, pp. 486-487).
\end{abstract}

Moseley $(1913,1914)$ found that the frequencies of the x-rays given off by cathode-ray tubes depended on the metal used as the anode. He found a linear relationship between the square root of the frequencies of the x-rays and the atomic number, viz., position of the element in the periodic table. This led him to conclude that the atomic number of an element is equal to the positive charge on the nucleus of an atom. Finally, the struggles of so many workers had borne fruit and the scientific community found a plausible cause of the periodicity of the elements as a function of atomic number. According to Heilbron (1966), one of the first post-Moseley periodic tables was built by Ladenburg (1920), which still had vacant spaces for elements 43, 61, 72 , and 75 .

\title{
Mendeleev's Periodic Law: Does it Follow a "Baconian Inductive Ascent”?
}

To understand what Lakatos (1970) refers to as the "Baconian inductive ascent" let us consider Bohr's model of the atom: “. . Bohr's problem was not to explain Balmer and Paschen series, but to explain the paradoxical stability of the Rutherford atom. Moreover, Bohr had not even heard of these formulae before he wrote the first version of his paper" (p. 147). This version of the events is corroborated in an extremely careful study by Heilbron and Kuhn (1969). Lakatos (1970) goes on to show the importance of this event in the history of science: "Since the Balmer and the Paschen series were known before 1913 [year of Bohr's first publication], some historians 
present the story as an example of a Baconian 'inductive ascent': (1) the chaos of spectrum lines, (2) an empirical law (Balmer), (3) the theoretical explanation (Bohr)" (p. 147).

A major premise of historians who follow the Baconian inductive ascent is that scientific theories and laws are primarily driven by experimental observations. Furthermore, such empiricist interpretations consider scientific progress to be dichotomous, viz., experimental observations lead to scientific laws, which later facilitate the elaboration of explanatory theories. On the contrary, Lakatos (1970) argues that, “. . . the clash is not 'between theories and facts' but between two high-level theories: between an interpretative theory to provide the facts and an explanatory theory to explain them; and the interpretative theory may be on quite as high a level as the explanatory theory" (p. 129). In other words, scientific progress is characterized by a series of theories or models (plausible explanations), which vary in the degree to which they explain/ interpret/predict the experimental findings.

It is plausible to suggest that the development of the periodic table can also be conceptualized as a Baconian inductive ascent by philosophers and textbook authors with an inductivist perspective, according to the following periods:

1. Early attempts to classify the elements starting from 1817 and the discovery of about 60 elements along with their physical and chemical properties. This period extended up to approximately 1860 and corresponds to the chaos of spectrum lines before Balmer's law.

2. Work in this period was stimulated by the Karlsruhe congress of 1860 and important contributions were made by De Chancourtois, Odling, Meyer, Newlands, and Hinrichs. Mendeleev, of course, has received major credit for having explicitly stated the periodic law in 1869 (this corresponds to Balmer's empirical law for the hydrogen line spectrum).

3. Work of Moseley $(1913,1914)$ and others finally provided an explanation of the periodic table based on atomic numbers - the modern form of the law, viz., properties of the elements are a periodic function of their atomic numbers (this corresponds to Bohr's explanation of the hydrogen line spectrum).

\section{Should Mendeleev's Contribution Could be Considered a Theory or an Empirical Law?}

There seems to be considerable controversy among philosophers of science with respect to the nature of Mendeleev's contribution. Wartofsky (1968) clearly considers Mendeleev's contribution to be more than a simple empirical law:

Mendeleev, for example, predicted that the blank space of atomic number 32, which lies between silicon and tin in the vertical column, would contain an element which was grayish-white, would be unaffected by acids and alkalis, and would give a white oxide when burned in air, and when he predicted also its atomic weight, atomic volume, density and boiling point, he was using the periodic table as a hypothesis from which predictions could be deduced. This was in 1871. (p. 203)

Ziman (1978) recognizes the importance of predictions with respect to the validity of a theory, and hence Mendeleev's contribution can be considered as a theory:

Needless to say, the most impressive way of validating a scientific theory is to confirm its predictions ... the persuasive power of a successful prediction arises from the fact that it could not have been deliberately contrived. The most famous examples, such as Mendel'eef's prediction of the existence and properties of undiscovered elements to fill the 
gaps in the periodic table, or Gell-Mann and Neeman's prediction of the Omega-minus particle to complete an $\mathrm{SU}(3)$ octet, have astonishing rhetorical power. (p. 31, original italics)

Shapere (1977) refers to the fact that, historically, Mendeleev's work has been referred to as a classification, system, table, or a law. Nevertheless, in his opinion, the periodic table is neither a law nor a theory but rather an ordered domain: “ . . . although the periodic table was widely referred to as a law, the general opinion of the time was that it could be called a 'law' only in a rather loose sense, the true law being the precise mathematical expression of the 'function' relating the atomic weights and the other properties of the elements ..." (p. 536).

Scerri and Worrall (2001) present a detailed study of Mendeleev's work and conclude that it was neither a law nor a theory but rather a codification scheme: “. . as scientists were interested in applying Mendeleev's scheme or simply thinking of it as a codification of the phenomena, it should make no difference at all whether some phenomenon of interest was predicted or accommodated in either sense" (p. 426). In a similar vein, Bensaude-Vincent (1986) suggests that Mendeleev:

... was able to accomplish the positivist ideal for a mature science: to summarize all the known facts and laws in a systematic table; ... Mendeleev belonged to a strict positivist tradition: his rejection of all hypotheses on the origin of the elements, his search of a single general law gathering the largest number of chemical data, his practice of classification, are all typical attitudes of the "esprit positif" according to A. Comte (p. 14).

This attribution of "esprit positif" to the work of Mendeleev, however, contrasts sharply with what Mendeleev himself had to say about his contribution:

If statements of fact themselves depend upon the person who observes them, how much more distinct is the reflection of the personality of him who gives an account of methods and of philosophical speculations which form the essence of science! For this reason there will inevitably be much that is subjective in every objective exposition of science (Preface to the sixth Russian edition, reproduced in Mendeleev, 1897, p. vii).

At this stage we contrast the views of philosophers of science with respect to Mendeleev's work (presented above) and the role of idealization in science. Most scientists and philosophers would consider Newton's law of gravitation as a paradigm case of a natural law, stated by Cartwright (1983) as: "Law of gravitation: $\mathrm{F}=\mathrm{Gmm}^{\prime} / \mathrm{r}^{2}$ " (p. 57). In spite of this Cartwright (1983) asks: "Does this law [gravitation] truly describe how bodies behave? (p. 57), and responds laconically: "Assuredly not” (p. 57). She explains further:

For bodies which are both massive and charged, the law of universal gravitation and Coulomb's law (the law that gives the force between two charges) interact to determine the final force. But neither law by itself truly describes how the bodies behave. No charged objects will behave just as the law of universal gravitation says; and any massive objects will constitute a counterexample to Coulomb's law. These two laws are not true: worse they are not even approximately true [a mathematical expression notwithstanding]. (p. 57, emphasis added)

Let us now consider an alternative account from a philosopher of science, which provides a way of understanding the practice of science without the laws of nature: 
But one need not appeal to history to deconstruct the concept of a law of nature. The concept is theoretically suspect as well. For example, any law of nature refers to only a few physical quantities. Yet nature contains many quantities which often interact one with another, and there are few if any truly isolated systems. So there cannot be many systems in the real world that exactly satisfy any purported law of nature. Consequently, understood as general claims about the world, most purported laws of nature are in fact false. So we need a portrait of science that captures our everyday understanding of success without invoking laws of nature understood as true, universal generalizations (Giere, 1995, p. 109).

Giere (1999) elaborates further with respect to "science without laws." It is of interest to observe how the conceptualizations of Wartofsky (1968) and Ziman (1978) coincide on the one hand, and the degree to which they differ with those of Bensaude-Vincent (1986), Shapere (1977), and Scerri and Worrall (2001). In contrast, Cartwright (1983), Giere (1995/1999), Lakatos (1970), and perhaps (!) Mendeleev (1897) conceptualize the problem in an entirely different framework, which in our opinion is quite helpful in understanding Mendeleev's periodic table. In other words, we do not necessarily have to follow the law/theory (or for that matter ordered domain/ codification scheme) dichotomy, but rather it is plausible to suggest that Mendeleev's work can be considered as an "interpretative" theory, which became "explanatory" (cf. Lakatos, 1970) after the periodic law was based on atomic numbers (Moseley, 1913, 1914). These considerations, if included in the textbooks, can facilitate students' understanding with respect to how scientific progress is laden with controversies, contradictions, and alternative interpretations.

\section{Criteria for Evaluation of General Chemistry Textbooks}

Based on the history and philosophy of science framework presented in the previous section, we present here criteria for the evaluation of freshman/college-level introductory chemistry textbooks:

1. The importance of accommodation in the development of the periodic table. Accommodation of the different elements in the periodic table according to their physical and chemical properties is considered an important factor in the success and acceptance of the periodic table. This criterion is based on Brush (1996) and van Spronsen (1969). The following classifications were elaborated:

Satisfactory (S): If the textbook explains and emphasizes that an important aspect of the periodic table is accommodation of the different elements with respect to atomic weight/number and various properties, such as density, atomic volume, atomic/ionic radii, ionization energy, electronegativity, electron affinity, formation of oxides and chlorides, etc.

Mention (M): A simple mention that accommodation was important.

No mention $(\mathrm{N})$ : No mention of the role played by accommodation.

2. The importance of prediction (contraprediction) as evidence to support the periodic law. After the discovery of gallium in 1875, chemists devoted more attention to the periodic law, and the table was increasingly recognized as an important tool for both education and research. This criterion is based on Akeroyd (1991), Brush (1996), and van Spronsen (1969). The following classifications were elaborated:

Satisfactory (S): If the textbook emphasizes the importance of prediction in the development of the periodic table by providing as an example at least one of the three elements gallium, scandium, or germanium, and a comparison of the predicted and experimental properties. 
Mention (M): A simple mention that Mendeleev made predictions of new elements, and provides as an example one or more of the three elements.

No mention $(\mathrm{N})$ : If the textbook states that Mendeleev made predictions with no examples.

3. Relative importance of accommodation and prediction in the development of the periodic table. There is considerable controversy among historians and philosophers of science with respect to the relative importance of accommodation and prediction. For science education it is important to note that the success of the periodic table could be attributed to accommodations, predictions, or both. This facilitates the understanding that the same experimental data can be explained by alternative interpretations. This criterion is based on Akeroyd (1991), Brush (1996), and Scerri and Worrall (2001). The following classifications were elaborated:

Satisfactory (S): If the textbook explicitly refers to the rivalry and conflicting interpretations with respect to the success of the periodic table; that is, due to accommodations or predictions.

Mention (M): A simple mention and comparison of alternate ways of explaining the success of the periodic table with no mention of rivalry and controversy.

No mention $(\mathrm{N})$ : If the textbook mentions the role played by accommodation and prediction with no attempt to compare nor mention the controversial role of the two.

4. The role of novel predictions. In contrast to contrapredictions ( $\mathrm{Ga}, \mathrm{Sc}$, and $\mathrm{Ge})$, Brush (1996) considers the correction of various atomic weights by Mendeleev as novel predictions. For example, in the case of Be, he accepted 9 instead of 14, U 240 instead of 120, and Te 125 instead of 128. This criterion is based on Brush (1996). The following classifications were elaborated:

Satisfactory (S): If the textbook recognizes the role of such novel predictions and provides at least one example as to how Mendeleev corrected atomic weights of the elements.

Mention (M): A simple mention, with at least one example, as to how Mendeleev inverted order of the elements, and no mention of correction of atomic weights.

No mention $(\mathrm{N})$ : No mention of novel predictions.

5. Explanation of periodicity in the periodic table. How does one explain the periodicity of the elements in the development of the periodic table? The idea behind this criterion is to make students aware that, before the electronic structure of the atom was discovered, different explanations were offered for periodicity. A historical reconstruction shows that this was a controversial issue and generally two alternatives were presented: (a) inductive generalization; and (b) periodicity as a function of the atomic theory, that is, before electronic configurations were definitively elaborated. This criterion is based on Bohr (1913), Brush (1996), Lewis (1923), Mendeleev (1869, 1879, 1889), Moseley (1913), Thomson (1897), and van Spronsen (1969). The following classifications were elaborated:

Satisfactory (S): If the textbook presents the two alternative interpretations, the controversy, and then accepts one and provides reasons for this selection. It is possible that the textbook may not accept any interpretation and leave this as an open question.

Mention (M): A simple mention of one or both alternatives with no details with respect to the merits of either interpretation.

No mention $(\mathrm{N})$ : No attempt to explain periodicity in the table.

6. Mendeleev's contribution: theory or an empirical law? This criterion tries to analyze the nature of Mendeleev's contribution and, hence, facilitates understanding of scientific progress. Given the controversy among philosophers of science, a historical reconstruction provides three alternatives: (a) an ordered domain or codification scheme; (b) an empirical law; and (c) a theory with limited explanatory power, or an interpretative theory. This criterion is based on Cartwright (1983), Giere (1995), 
Lakatos (1970), Scerri and Worrall (2001), Shapere (1977), Wartofsky (1968), and Ziman (1978). The following classifications were elaborated:

Satisfactory (S): If the textbook emphasizes the problematic nature of understanding scientific progress and provides reasons for accepting any one of the three alternatives. It is possible that the textbook may not accept any alternative and leave this as an open question.

Mention (M): If the textbook accepts any one of the three alternatives and makes no reference to the controversy with respect to scientific progress.

No mention $(\mathrm{N})$ : No attempt to understand the nature of Mendeleev's periodic table.

7. Development of the periodic table as a progressive sequence of heuristic principles. According to Lakatos (1970), scientific progress is characterized by heuristic principles that increase the interpretative/explanatory power of a theory. A historical reconstruction of the periodic table shows that it can be understood as a progressive sequence of heuristic principles based on the following contributions: (a) early ideas about atomic theory and accumulation of data with respect to the atomic weights of the elements and their properties; (b) the first attempt to classify the elements by Döbereiner (1817), and later by De Chancourtois (1862), Odling (1864), Meyer (1864), Newlands (1865), Hinrichs (1866), and other attempts before Mendeleev. It would suffice if the textbook refers to anyone of these contributions. (c) Mendeleev's first periodic table in 1869 based on atomic weights and subsequent contributions; (d) discovery of argon in 1895 and its accommodation in the periodic table; and (e) the contribution of Moseley (1913) and the modern periodic table based on atomic numbers. This criterion is based on Brush (1996), Giunta (2001), Kragh (2000), Lakatos (1970), Robinson (2000), and van Spronsen (1969). The following classifications were elaborated:

Satisfactory (S): If the textbook emphasizes the importance of the five heuristic principles and provides some semblance of a sequence (so as to "weave" the text) that increases the heuristic/explanatory power of the periodic table.

Mention (M): Although the textbook may not establish a sequence explicitly, it should mention at least four of the five heuristic principles.

No mention $(\mathrm{N})$ : A simple inclusion of three of the heuristic principles with no attempt to establish a sequence (most textbooks include Mendeleev and Moseley or that the modern periodic table is based on atomic numbers).

\section{Method}

Methodology used in this study went through various stages that can be summarized as: (a) a historical reconstruction of the various attempts to develop/construct the periodic table; (b) elaboration of criteria based on the historical reconstruction; and (c) evaluation of general chemistry textbooks based on the criteria. In what follows, guidelines for selection of textbooks and a procedure for implementing the criteria are presented.

\section{Guidelines for Selection of Textbooks}

A number of guidelines were established: (a) Availability of most textbooks in libraries. (b) Inclusion of recent textbooks (13 textbooks in this study were published between 2000 and 2002). (c) Inclusion of textbooks that have published various editions, which shows their acceptance by chemistry teachers [examples include: (i) Atkins \& Beran, 1992; Atkins \& Jones, 2002; Jones \& Atkins, 2000; (ii) Brady, 2000; Brady \& Holum, 1981; Brady \& Humiston, 1996; Brady, Russell, \& Holum, 2000; (iii) Hill \& Petrucci, 1999; Petrucci, 1989; Petrucci \& Harwood, 1997]. (d) Inclusion of textbooks that were published before 1990, in order to compare them with more recent 
textbooks (23 textbooks in this study were published between 1966 and 1989). (e) Consultations with colleagues in different parts of the world revealed that various textbooks included in this study are used as translations (examples: Spanish, Portuguese, and Italian). (f) Various studies published in this journal and other science education journals have used these textbooks. This shows that textbooks included in this study are quite representative of those used in various parts of the world.

\section{Procedure for Implementing the Criteria}

To implement the criteria the following procedure was followed: (a) First evaluation: the first and third authors applied the criteria separately to evaluate three textbooks (selected randomly). Both evaluators agreed on the evaluation of four criteria on the first textbook, five on the second, and all seven criteria on the third. With this experience, both authors evaluated the remaining textbooks. (b) Second evaluation: the second and third authors applied the criteria separately to evaluate three textbooks (selected randomly). Both authors agreed on the evaluation of five criteria on the first textbook, six criteria on the second, and all seven criteria on the third. With this experience, both authors evaluated the remaining textbooks, with the numbers on which there was coincidence as follows (based on 54 textbooks): Criterion 1, 51; Criterion 2, 52; Criterion 3, 48; Criterion 4, 46; Criterion 5, 44; Criterion 6, 53; and Criterion 7, 43. All differences were resolved by discussion. It is important to note that there was agreement of $90 \%$ or more on all criteria between the first and the second evaluation. A few elements in the first six criteria overlapped with some aspects of Criterion 7. However, this was not a problem, because, in Criterion 7, these elements played a different role, as it was expected that the textbook would "weave" (semblance of a sequence) these elements into a story.

\section{Evaluation of Chemistry Textbooks: Results and Discussion}

\section{Criterion 1 (Importance of Accommodation in Development of the Periodic Table)}

Of the 57 textbooks analyzed in this study (see Tables 1 and 2), 55 presented a satisfactory (S) description of the importance of accommodation of the elements according to their physicochemical properties in the periodic table. Most textbooks devoted 20 or more pages, including color photographs and three-dimensional figures. One textbook gave the following advice to the students: "It is extremely important for you to connect the configuration of an element and its position in the periodic table, since this will allow you to organize a large number of chemical facts" (Kotz \& Purcell, 1991, p. 325, original italics). Another textbook was more explicit and stated: "The arrangements of the elements in the periodic table correlate with the subshells that hold the highest-energy electrons" (Reger, et al., 1997, p. 290). This shows that the textbooks are fully aware of the role played by accommodation in the development of the periodic table.

\section{Criterion 2 (Importance of Prediction as Evidence to Support the Periodic Law)}

Thirty textbooks emphasized the importance of prediction (contraprediction; cf. Brush, 1996) satisfactorily (S) as evidence to support the periodic law and, of these, 29 textbooks compared the properties of at least one of the predicted elements $(\mathrm{Ga}, \mathrm{Sc}$, and $\mathrm{Ge})$ with the experimental values. This comparison was presented in the form of a table occupying about one half of a page. Most textbooks presented arguments to emphasize the role of predictions; for instance: "It was the extraordinary success of Mendeléeff's predictions that led chemists not only to accept the periodic 
Table 1

Evaluation of chemistry textbooks based on a history and philosophy of science framework (periodic table)

\begin{tabular}{|c|c|c|c|c|c|c|c|c|c|}
\hline \multirow[b]{2}{*}{ No. } & \multirow[b]{2}{*}{ Textbook } & \multicolumn{7}{|c|}{ Criteria $^{\mathrm{a}}$} & \multirow[b]{2}{*}{ Points } \\
\hline & & 1 & 2 & 3 & 4 & 5 & 6 & 7 & \\
\hline 1 & Ander and Sonnessa (1968) & $\mathrm{S}$ & $\mathrm{N}$ & $\mathrm{N}$ & $\mathrm{N}$ & $\mathrm{N}$ & $\mathrm{N}$ & M & 3 \\
\hline 2 & Anderson, Ford, and Kennedy (1973) & $\mathrm{S}$ & M & $\mathrm{N}$ & $\mathrm{N}$ & $\mathrm{N}$ & $\mathrm{N}$ & $\mathrm{N}$ & 3 \\
\hline 3 & Atkins and Beran (1992) & $\mathrm{S}$ & $\mathrm{N}$ & $\mathrm{N}$ & $\mathrm{N}$ & M & $\mathrm{N}$ & $\mathrm{N}$ & 3 \\
\hline 4 & Atkins and Jones (2002) & $\mathrm{S}$ & $\mathrm{S}$ & $\mathrm{N}$ & $\mathrm{N}$ & M & $\mathrm{N}$ & M & 6 \\
\hline 5 & Bishop (2002) & M & $\mathrm{N}$ & $\mathrm{N}$ & $\mathrm{N}$ & $\mathrm{N}$ & $\mathrm{N}$ & $\mathrm{N}$ & 1 \\
\hline 6 & Bodner and Pardue (1989) & $\mathrm{S}$ & $\mathrm{S}$ & $\mathrm{N}$ & $\mathrm{S}$ & $\mathrm{N}$ & $\mathrm{N}$ & $\mathrm{N}$ & 6 \\
\hline 7 & Brady (2000) & $\mathrm{S}$ & M & $\mathrm{N}$ & M & $\mathrm{N}$ & $\mathrm{N}$ & M & 5 \\
\hline 8 & Brady and Holum (1981) & $\mathrm{S}$ & $\mathrm{S}$ & $\mathrm{N}$ & $\mathrm{S}$ & M & $\mathrm{N}$ & M & 8 \\
\hline 9 & Brady and Humiston (1996) & $\mathrm{S}$ & $\mathrm{S}$ & $\mathrm{N}$ & M & $\mathrm{N}$ & $\mathrm{N}$ & M & 6 \\
\hline 10 & Brady et al. (2000) & $\mathrm{S}$ & $\mathrm{S}$ & $\mathrm{N}$ & $\mathrm{S}$ & M & $\mathrm{N}$ & $\mathrm{M}$ & 8 \\
\hline 11 & Brown, LeMay, and Bursten (1997) & $\mathrm{S}$ & $\mathrm{S}$ & $\mathrm{N}$ & $\mathrm{N}$ & $\mathrm{N}$ & $\mathrm{N}$ & M & 5 \\
\hline 12 & Burns (1995) & $\mathrm{S}$ & M & $\mathrm{N}$ & M & $\mathrm{N}$ & $\mathrm{N}$ & $\mathrm{N}$ & 4 \\
\hline 13 & Chang (1998) & $\mathrm{S}$ & $\mathrm{S}$ & $\mathrm{N}$ & $\mathrm{N}$ & $\mathrm{N}$ & $\mathrm{N}$ & M & 5 \\
\hline 14 & Daub and Seese (1996) & $\mathrm{S}$ & M & $\mathrm{N}$ & M & $\mathrm{N}$ & $\mathrm{N}$ & M & 5 \\
\hline 15 & Dickerson et al. (1984) & $\mathrm{S}$ & $\mathrm{S}$ & $\mathrm{N}$ & $\mathrm{N}$ & $\mathrm{N}$ & $\mathrm{N}$ & M & 5 \\
\hline 16 & Dickson (2000) & $\mathrm{S}$ & $\mathrm{N}$ & $\mathrm{N}$ & $\mathrm{N}$ & M & $\mathrm{N}$ & M & 4 \\
\hline 17 & Dillard and Goldberg (1971) & $\mathrm{S}$ & $\mathrm{N}$ & $\mathrm{N}$ & $\mathrm{N}$ & $\mathrm{N}$ & $\mathrm{N}$ & $\mathrm{N}$ & 2 \\
\hline 18 & Ebbing (1996) & $\mathrm{S}$ & $\mathrm{S}$ & M & $\mathrm{N}$ & $\mathrm{N}$ & $\mathrm{N}$ & $\mathrm{N}$ & 5 \\
\hline 19 & Goldberg (2001) & $\mathrm{S}$ & M & $\mathrm{N}$ & $\mathrm{S}$ & M & $\mathrm{N}$ & $\mathrm{N}$ & 6 \\
\hline 20 & Gray and Haight (1983) & $\mathrm{S}$ & $\mathrm{S}$ & $\mathrm{N}$ & $\mathrm{S}$ & $\mathrm{N}$ & $\mathrm{N}$ & M & 7 \\
\hline 21 & Hein and Arena (1997) & $\mathrm{S}$ & $\mathrm{N}$ & $\mathrm{N}$ & $\mathrm{N}$ & M & $\mathrm{N}$ & $\mathrm{N}$ & 3 \\
\hline 22 & Hill and Petrucci (1999) & $\mathrm{S}$ & $\mathrm{S}$ & $\mathrm{N}$ & M & M & $\mathrm{N}$ & $\mathrm{N}$ & 6 \\
\hline 23 & Holtzclaw and Robinson (1988) & $\mathrm{S}$ & $\mathrm{S}$ & $\mathrm{N}$ & $\mathrm{N}$ & $\mathrm{N}$ & $\mathrm{N}$ & $\mathrm{N}$ & 4 \\
\hline 24 & Joesten et al. (1991) & $\mathrm{S}$ & $\mathrm{S}$ & $\mathrm{N}$ & M & $\mathrm{N}$ & $\mathrm{N}$ & M & 6 \\
\hline 25 & Jones and Atkins (2000) & $\mathrm{S}$ & $\mathrm{S}$ & $\mathrm{N}$ & $\mathrm{N}$ & M & $\mathrm{N}$ & M & 6 \\
\hline 26 & Kotz and Purcell (1991) & $\mathrm{S}$ & M & M & M & M & $\mathrm{N}$ & $\mathrm{N}$ & 6 \\
\hline 27 & Lippincott et al. (1977) & $\mathrm{S}$ & $\mathrm{S}$ & M & $\mathrm{N}$ & $\mathrm{N}$ & M & M & 7 \\
\hline 28 & Mahan and Myers (1987) & $\mathrm{S}$ & M & $\mathrm{N}$ & $\mathrm{S}$ & $\mathrm{N}$ & $\mathrm{N}$ & $\mathrm{N}$ & 5 \\
\hline 29 & Malone (2001) & $\mathrm{S}$ & M & $\mathrm{N}$ & $\mathrm{S}$ & $\mathrm{N}$ & $\mathrm{N}$ & M & 6 \\
\hline 30 & Masterton and Hurley (1993) & $\mathrm{S}$ & $\mathrm{S}$ & $\mathrm{N}$ & $\mathrm{N}$ & $\mathrm{N}$ & $\mathrm{N}$ & $\mathrm{N}$ & 4 \\
\hline 31 & Masterton et al. (1985) & $\mathrm{S}$ & $\mathrm{S}$ & $\mathrm{N}$ & $\mathrm{N}$ & $\mathrm{N}$ & $\mathrm{N}$ & M & 5 \\
\hline 32 & McMurry and Fay (2001) & $\mathrm{S}$ & $\mathrm{S}$ & M & $\mathrm{N}$ & $\mathrm{N}$ & M & M & 7 \\
\hline 33 & Miller (1969) & M & $\mathrm{N}$ & $\mathrm{N}$ & $\mathrm{N}$ & $\mathrm{N}$ & $\mathrm{N}$ & $\mathrm{N}$ & 1 \\
\hline 34 & Moore et al. (2002) & $\mathrm{S}$ & M & $\mathrm{N}$ & $\mathrm{N}$ & M & $\mathrm{N}$ & $\mathrm{N}$ & 4 \\
\hline 35 & Mortimer (1983) & $\mathrm{S}$ & M & $\mathrm{N}$ & M & $\mathrm{N}$ & $\mathrm{N}$ & M & 5 \\
\hline 36 & Newell (1977) & $\mathrm{S}$ & M & $\mathrm{N}$ & $\mathrm{N}$ & $\mathrm{N}$ & $\mathrm{N}$ & $\mathrm{N}$ & 3 \\
\hline 37 & O’Connor (1974) & $\mathrm{S}$ & $\mathrm{N}$ & $\mathrm{N}$ & $\mathrm{N}$ & $\mathrm{N}$ & $\mathrm{N}$ & M & 3 \\
\hline 38 & Oxtoby et al. (1994) & $\mathrm{S}$ & $\mathrm{S}$ & $\mathrm{N}$ & M & $\mathrm{N}$ & $\mathrm{N}$ & M & 6 \\
\hline 39 & Petrucci (1989) & $\mathrm{S}$ & $\mathrm{S}$ & $\mathrm{N}$ & $\mathrm{S}$ & $\mathrm{N}$ & $\mathrm{N}$ & M & 7 \\
\hline 40 & Petrucci and Harwood (1997) & $\mathrm{S}$ & $\mathrm{S}$ & $\mathrm{N}$ & $\mathrm{S}$ & $\mathrm{N}$ & $\mathrm{N}$ & M & 7 \\
\hline 41 & Phillips et al. (2000) & $\mathrm{S}$ & $\mathrm{S}$ & M & M & $\mathrm{N}$ & M & M & 8 \\
\hline 42 & Quagliano and Vallarino (1969) & $\mathrm{S}$ & $\mathrm{S}$ & $\mathrm{N}$ & M & $\mathrm{N}$ & $\mathrm{N}$ & M & 6 \\
\hline 43 & Reger et al. (1997) & $\mathrm{S}$ & M & $\mathrm{N}$ & $\mathrm{N}$ & $\mathrm{N}$ & $\mathrm{N}$ & $\mathrm{M}$ & 4 \\
\hline 44 & Russo and Silver (2002) & $\mathrm{S}$ & $\mathrm{S}$ & $\mathrm{N}$ & $\mathrm{N}$ & $\mathrm{N}$ & $\mathrm{N}$ & $\mathrm{N}$ & 4 \\
\hline 45 & Segal (1989) & $\mathrm{S}$ & M & M & $\mathrm{N}$ & $\mathrm{N}$ & $\mathrm{N}$ & $\mathrm{N}$ & 4 \\
\hline 46 & Sienko and Plane (1971) & $\mathrm{S}$ & $\mathrm{N}$ & $\mathrm{N}$ & $\mathrm{N}$ & $\mathrm{N}$ & $\mathrm{N}$ & $\mathrm{N}$ & 2 \\
\hline 47 & Silberberg (2000) & $\mathrm{S}$ & $\mathrm{S}$ & $\mathrm{N}$ & $\mathrm{N}$ & $\mathrm{N}$ & $\mathrm{N}$ & M & 5 \\
\hline 48 & Sisler et al. (1980) & $\mathrm{S}$ & M & $\mathrm{N}$ & $\mathrm{N}$ & M & M & M & 6 \\
\hline 49 & Slabaugh and Parsons (1966) & $\mathrm{S}$ & M & $\mathrm{N}$ & $\mathrm{N}$ & $\mathrm{N}$ & $\mathrm{N}$ & M & 4 \\
\hline 50 & Spencer et al (1999) & $\mathrm{S}$ & $\mathrm{N}$ & $\mathrm{N}$ & $\mathrm{N}$ & $\mathrm{N}$ & $\mathrm{N}$ & $\mathrm{N}$ & 2 \\
\hline 51 & Stoker (1990) & $\mathrm{S}$ & $\mathrm{N}$ & $\mathrm{N}$ & $\mathrm{N}$ & M & M & $\mathrm{N}$ & $\begin{array}{c}4 \\
\text { ontinued) }\end{array}$ \\
\hline
\end{tabular}


Table 1

(Continued)

\begin{tabular}{llllllllll}
\hline & \multicolumn{7}{c}{ Criteria $^{\mathrm{a}}$} \\
\cline { 3 - 7 } No. & \multicolumn{1}{c}{ Textbook } & 1 & 2 & 3 & 4 & 5 & 6 & 7 & Points \\
\hline 52 & Umland (1993) & $\mathrm{S}$ & $\mathrm{S}$ & $\mathrm{N}$ & $\mathrm{M}$ & $\mathrm{N}$ & $\mathrm{N}$ & $\mathrm{N}$ & 5 \\
53 & Umland and Bellama (1999) & $\mathrm{S}$ & $\mathrm{S}$ & $\mathrm{N}$ & $\mathrm{M}$ & $\mathrm{M}$ & $\mathrm{N}$ & $\mathrm{N}$ & 6 \\
54 & Whitten, Davis, and Peck (1996) & $\mathrm{S}$ & $\mathrm{S}$ & $\mathrm{N}$ & $\mathrm{M}$ & $\mathrm{N}$ & $\mathrm{N}$ & $\mathrm{N}$ & 5 \\
55 & Wolfe (1988) & $\mathrm{S}$ & $\mathrm{S}$ & $\mathrm{N}$ & $\mathrm{N}$ & $\mathrm{N}$ & $\mathrm{N}$ & $\mathrm{N}$ & 4 \\
56 & Wood et al. (1968) & $\mathrm{S}$ & $\mathrm{N}$ & $\mathrm{N}$ & $\mathrm{N}$ & $\mathrm{N}$ & $\mathrm{N}$ & $\mathrm{N}$ & 2 \\
57 & Zumdahl (1993) & $\mathrm{S}$ & $\mathrm{S}$ & $\mathrm{N}$ & $\mathrm{S}$ & $\mathrm{N}$ & $\mathrm{N}$ & $\mathrm{M}$ & 7 \\
\hline
\end{tabular}

Note: Textbooks were awarded the following points: satisfactory (S), 2 points; mention (M), 1 point; no mention $(\mathrm{N}), 0$ point.

${ }^{\text {a }}$ Criteria: 1 - the importance of accommodation in the development of the periodic table; 2 - the importance of prediction (contraprediction) as evidence to support the periodic law; 3 -relative importance of accommodation and prediction in the development of the periodic table; 4 - the role of novel predictions; 5-explanation of periodicity in the periodic table; 6 Mendeleev's contribution: theory or an empirical law?; 7-development of the periodic table as a progressive sequence of heuristic principles.

table but to recognize Mendeléeff more than anyone else as the originator of the concept on which it was based" (Bodner \& Pardue, 1989, p. 201). According to Hill and Petrucci (1999): "The predictive nature of Mendeleev's periodic table led to its wide acceptance as tremendous scientific accomplishment" (p. 45, original italics). One of the textbooks (Phillips, Strozak, \& Wistrom, 2000) compared the prediction of the elements and their properties to that of Halley's comet, which repeats its cycle every 76 years, and included an exercise in which the students are asked to predict the properties of an unknown element $(\mathrm{Ge})$, while having the properties of $\mathrm{Si}, \mathrm{Ga}, \mathrm{As}$, and Sn. Twenty-five textbooks reproduced Mendeleev's 1871 periodic table (at times in color and various devices to highlight missing elements), occupying about one half of a page to emphasize the elements predicted.

\section{Criterion 3 (Relative Importance of Accommodation and Prediction in Development of the Periodic Table)}

None of the textbooks explained satisfactorily (S) and only six made a mention $(\mathrm{M})$ of alternative interpretations with respect to the success of the periodic table. One textbook came quite close to having a satisfactory presentation:

Table 2

Distribution of chemistry textbooks according to criteria and classification

\begin{tabular}{lrrr}
\hline & \multicolumn{3}{c}{ Classification $^{\text {a }}$} \\
\cline { 2 - 4 } Criteria & N & M & S \\
\hline 1 & 0 & 2 & 55 \\
2 & 12 & 15 & 30 \\
3 & 51 & 6 & 0 \\
4 & 33 & 14 & 10 \\
5 & 43 & 5 & 0 \\
6 & 52 & 30 & 0 \\
7 & 27 & 50 \\
\hline
\end{tabular}

${ }^{\mathrm{a} C l a s s i f i c a t i o n: ~ S, ~ s a t i s f a c t o r y ; ~ M, ~ m e n t i o n ; ~ N, ~ n o ~ m e n t i o n . ~}$ 
Any good hypothesis must do two things: It must explain known facts, and it must make predictions about phenomena yet unknown... Mendeleev's hypothesis about how known chemical information could be organized passed all tests. Not only did the periodic table arrange data in a useful and consistent way to explain known facts about chemical reactivity, it also led to several remarkable predictions that were later found to be accurate. (McMurry \& Fay, 2001, p. 160)

This is a fairly good presentation of Mendeleev's dilemma (hypothesis) and could have been classified satisfactory had the authors recognized the role of controversy and alternative interpretations. In what follows are some of the examples of other textbooks classified as M:

The periodic table discussed in this chapter is an example of descriptive classification and ordering. Mendeleev... found... that there was a correlation between properties and atomic weights ... which permitted the elements to be ordered within the groups. The precision with which this information permitted assignment of properties is illustrated by Mendeleev's prediction of the properties of the element he called ekasilicon. (Lippincott et al., 1977, p. 305)

More than 100 years later, we recognize Mendeleev's work as a milestone because he had the genius to realize that: (a) there were many elements yet to be discovered and (b) the characteristics of an element could be predicted from its atomic weight (and its position in his table). (Kotz \& Purcell, 1991, p. 334)

This shows that textbooks do recognize the importance of accommodations (Criterion 1) and predictions (Criterion 2), but not the relative importance of the two (Criterion 3). The inclusion of alternative interpretations could facilitate students' understanding of how progress in science inevitably leads to controversies and rivalries and, at times, it is extremely difficult to foresee and predict all implications of a theory. On the contrary, presentations of most textbooks lead students to believe that Mendeleev was successful (and not others) because he was a genius.

\section{Criterion 4 (Role of Novel Predictions)}

It is of interest to note that, in contrast to Criterion 2 (30 textbooks had $\mathrm{S}$ and $12 \mathrm{~N}$ ), in Criterion 4, 10 textbooks had a satisfactory (S) presentation and 33 had no mention $(\mathrm{N})$. Apparently, textbooks gave more importance to contrapredictions (Criterion 2, unknown elements) than novel predictions (Criterion 4, known elements). This coincides to a certain degree with Brush's (1996, p. 609) finding that no American or British textbooks mentioned the periodic law at all until after the discovery of gallium in 1875 by Boisbaudran, and Mendeleev's claim of having predicted its properties (see also Partington, 1948, pp. 348-349). Interestingly, the wellknown British chemist, William Crookes (1832-1919), recognized this early: "The prevision of phenomena not yet observed has been rightly declared by methodologists to be one of the principal distinctions between science, in the strict sense of the term, and a mere accumulation of unorganized knowledge; the discovery of gallium thus shows the value of Mendeleev's theory" (Crookes, 1877, p. 296).

The following is an example of a textbook that was classified as satisfactory (S):

Two elements, tellurium (Te) and iodine (I), caused Mendeleev some problems. According to the best estimates at that time, the atomic mass of tellurium was greater than that of iodine. Yet if these elements were placed in the table according to their atomic masses, 
they would not fall into the proper groups required by their properties. Therefore, Mendeleev switched their order and in so doing violated his own periodic law. (Actually, he believed that the atomic mass of tellurium had been incorrectly measured, but this wasn't so.) (Brady et al., 2000, p. 63)

This shows the complexity of placing the elements in the periodic table and how, in this case, Mendeleev was also misled, because the atomic mass of Te is indeed greater than that of I.

\section{Criterion 5 (Explanation of Periodicity in the Periodic Table)}

The objective behind this criterion was to make students think and reason with respect to the possible causes of periodicity in the periodic table. Many students must have wondered how a simple arrangement could provide such regularities. Textbooks could promote students' curiosity, and an historical reconstruction of the periodic table provides an opportunity to facilitate this objective by emphasizing: (a) inductive generalization, and (b) periodicity as a function of atomic theory. Apparently, none of the textbooks accomplished this objective satisfactorily (S), 14 made a simple mention (M), and 43 simply ignored the issue by no mention (N). It is important to note that even those textbooks that ignored the issue implicitly recognized that the periodic table was a consequence of the accumulation of experimental data. Of the 14 textbooks classified as mention (M) some emphasized inductive generalization, with the following two examples:

Mendeleev's approach to the periodic table was empirical; he based his classification scheme on the observed facts. (Hill \& Petrucci, 1999, p. 316, original italics)

The periodic table was created by Mendeleev to summarize experimental observations. He had no theory or model to explain why all alkaline earths combine with oxygen in a 1:1 atom ratio- they just do. (Moore et al., 2002, p. 266)

In what follows are two examples of textbooks classified as mention (M) and in which an attempt was made to highlight the role played by atomic theory in the development of the periodic table:

Many atomic masses were determined as a direct result of Dalton's postulates and the work that they stimulated, and scientists attempted to relate the atomic masses of the elements to the elements' properties. This work culminated in the development of the periodic table by Dmitry Mendeleyev (1834-1907).... (Goldberg, 2001, pp. 87-88)

Early in the nineteenth century, when Dalton's atomic theory was winning general acceptance, the first attempts were made toward classification of the elements into groups or families on the basis of similarities of physical and chemical properties...even in its primitive form as stated in 1869 , this [periodic] law clearly pointed to regularities that hinted at an orderly subatomic structure of matter and provided a tremendous stimulus toward seeking to understand the internal structure of atoms, as chemists and physicists sought to construct an atomic model that would explain Mendeleev's generalization. (Sisler et al., 1980, p. 150)

One of the textbooks classified as mention (M) combined both interpretations. Role of inductive generalization: "Observations of the similarities and differences in the behavior of elements stimulated the curiosity of many chemists. Was there a grand pattern to such similarities? 
If such a pattern existed, what message did it convey about the nature of matter?" (Dickson, 2000, p. 122). Regarding the role of atomic theory:

In the $1800 \mathrm{~s}$, the atomic theory captured the imagination of chemists... many new elements were discovered and added to the list of previously known elements. Information about elements began to accumulate. During these times, scientists became aware that the properties of some elements were very similar. Eventually, they noticed that some periodic or repeating pattern of properties existed among the elements (Dickson, 2000, p. 121).

In light of the historical reconstruction presented, to state that the periodic table was empirical and that Mendeleev had no theory or model to explain the periodicity of the properties of the elements, is perhaps rather simplistic and difficult to sustain. It is more fruitful and plausible to present a more balanced picture to the students by highlighting the dilemma faced by Mendeleev (and others) in which they endeavored to look for underlying patterns to explain and understand periodicity.

\section{Criterion 6 (Mendeleev's Contribution: Theory or Empirical Law?)}

This criterion is essential in understanding the nature of Mendeleev's contribution, viz., what exactly was he trying to do with all the information available. Mendeleev's own ambivalence notwithstanding, the historical reconstruction shows that Mendeleev's ingenuity consisted of precisely not only recognizing that the periodic table was a "legitimate induction from the verified facts" but that there was a reason/cause/explanation for this periodicity, viz., the atomic theory. In other words, scientists do not decide beforehand that their contribution would be empirical/ theoretical, but rather the scientific endeavor inevitably leads them to "speculate" with respect to underlying patterns of what they observe. Mendeleev's case is an eloquent example of this dilemma.

None of the textbooks made a satisfactory (S) presentation and 52 made no mention $(\mathrm{N})$ and hence ignored the issue. Only five textbooks made a simple mention (M) and, of these, Lippincott et al. (1977) considered the periodic table to an ordered domain: "If we examine the nature of scientific studies, we find that they always start with a group of observations collected as the data available for contemplation. The second step in the study is that of classification of data into recognizable related groupings ... The periodic table ... is an example of descriptive classification and ordering" (pp. 304-305, original italics).

Stoker (1990) considered Mendeleev's contribution to be an empirical law:

Indeed, the periodic table is considered to be the single most useful study aid available for organizing information about the elements. For many years after the formulation of the periodic law and the periodic table, both were considered to be empirical. The law worked and the table was very useful, but there was no explanation available for the law or for why the periodic table had the shape it had. It is now known that the theoretical basis for both the periodic law and the periodic table lies in electronic theory. (p. 155)

This presentation is quite representative of most textbooks. It ignores the fact that scientists were constantly trying to look for a "theoretical basis" of the periodic table, including Mendeleev himself. However, to state that for many years the table had no explanation is to ignore that progress in science is always tentative. In other words, our theories can hardly be considered to be final-in the future we may find a better explanation of the periodic table than that provided by the electronic theory. Research in science education has also recognized that tentativeness of theories is an important characteristic of nature of science (McComas et al., 1998; Niaz, 2001). 
McMurry and Fay (2001) provide an example of how Mendeleev's contribution can be considered a theory:

In many ways, the creation of the periodic table by Dmitri Mendeleev in 1869 is an ideal example of how a scientific theory comes into being. At first, there is only random information - a large number of elements and many observations about their properties and behavior. As more and more facts become known, people try to organize the data in ways that make sense, until ultimately a consistent hypothesis emerges. (p. 160)

As we have observed in this study the development of the periodic table is much more complex. Nevertheless, recognition of the role played by "emerging hypotheses" can facilitate a better understanding of the vicissitudes faced by Mendeleev and others, in their struggle to go beyond the observable entities.

\section{Criterion 7 (Development of the Periodic Table as a Progressive Sequence of Heuristic Principles)}

The objective of this criterion is to present ("weave") the development of the periodic table as a sequence of heuristic principles that seem thought-provoking, coherent, and plausible, and thus motivate students to understand that there is more to scientific progress than simple accumulation of data. None of the textbooks made a satisfactory (S) presentation; that is, to "weave" the five heuristic principles to provide semblance of a sequence in the form of a convincing argument. Thirty textbooks simply mentioned (M) at least four of the five principles, and 27 textbooks were classified as no mention (N).

One textbook (Phillips et al., 2000) takes almost 1.5 pages to explain Döbereiner's triads and showed that the properties of the elements had a relationship to their atomic mass. Petrucci (1989) uses a phone book analogy; that is, only if the phone book is arranged alphabetically by the last name can you readily find the phone number you are seeking: "The situation faced by nineteenth century chemists was similar. They had plenty of information about the behavior of elements and compounds, but they needed to find a way of organizing this information" (p. 276). Chang (1998, p. 289) presents the progressive increase in the number of known elements graphically (about one half of a page) from $1675(\approx 15), 1800(\approx 30), 1850(\approx 60), 1900(\approx 80), 1950(\approx 100)$, and 2000 (112). Dickson (2000, p. 70) presents similar information in the form of a bar graph (about one third of a page).

\section{Do Textbooks Present the Periodic Table as a "Baconian Inductive Ascent"?}

Following Lakatos (1970), a Baconian inductive ascent would incorporate the following sequence of periods: (a) accumulation of data with respect to the elements and early attempts at classification, starting in 1817; (b) postulation of Mendeleev's periodic law in 1869, as an inductive generalization (based on atomic mass); and (c) explanation of the periodic law based on the work of Moseley (1913) and the electronic theory (based on atomic number). Most textbooks explicitly refer to one or two of the periods. The following six textbooks explicitly refer to the three periods and their presentation can be considered a "Baconian inductive ascent": Brady et al. (2000), Hill \& Petrucci (1999), Kotz \& Purcell (1991), Lippincott et al. (1977), Sisler et al. (1980), and Umland (1993). Three examples are provided here:

Brady et al. (2000): 
(a) The need for organization was recognized by many early chemists, and there were numerous attempts to discover relationships among the chemical and physical properties of the elements. (p. 61)

(b) On the basis of extensive observations of this type, Mendeleev devised the original form of the periodic law. (p. 62, emphasis in original)

(c) Apparently, then, atomic mass was not the true basis for the periodic repetition of the properties of the elements. To determine what the true basis was, however, scientists had to await the discoveries of the atomic nucleus, the proton, and atomic numbers. (p. 63, emphasis added)

\section{Hill and Petrucci (1999):}

(a) In the nineteenth century, chemists discovered elements at a rapid rate. By 1830, 55 elements were known, all with different properties and no apparent pattern among them. (p. 45)

(b) Mendeleev's approach to the periodic table was empirical; he based his classification scheme on the observed facts. (p. 316, original italics)

(c) ...we will learn that Mendeleev's scheme also makes sense from a theoretical standpoint. We will first learn how electrons are distributed among the regions of an atom described by atomic orbitals, a description called the electron configuration of the atom. Then we will explore electron configurations as a basis for the periodic table. (p. 316, original italics)

\section{Kotz and Purcell (1991):}

(a) In the 19th century many chemists tried to find relationships between atomic weights and the properties of the elements. These efforts largely failed because atomic weights were not known for all the elements, and many measured values were inaccurate. (p. 334)

(b) In spite of Mendeleev's great achievement, problems arose when new elements were discovered and more accurate atomic weights determined... The fault lies with Mendeleev's assumption that the properties of the elements are periodic functions of their atomic weight. (p. 334, emphasis added)

(c) Indeed, if the elements are arranged in order of increasing atomic number, the defects in the Mendeleev table are corrected. It was therefore Moseley who discovered the law of chemical periodicity: the properties of the elements are periodic functions of their atomic numbers. (p. 334, emphasis in the original and italics added)

These presentations are problematic for various reasons. (a) No scientist can be aware/ foretell that his contribution would constitute the true basis of observed phenomena. (b) Mendeleev's faults and defects were not considered so by his contemporaries. (c) No one in 1869 or 1879 or 1889 , or for that matter until 1913 , could tell that the atomic number and not atomic weight was the "true basis" of the periodic table. (d) It is only with hindsight that we can refer to the true basis, faults, and defects in Mendeleev's contribution. (e) How can we know that the atomic number is the final explanation of the periodic table - a more fundamental particle (perhaps quarks!) may change this true basis. It is plausible to suggest that textbooks can provide students with a better appreciation of scientific progress by emphasizing the tentative nature of science. Burbules and Linn (1991, p. 232) explain cogently that if the history of science shows anything, it is precisely that, in the long run, all theories more or less turn out to be "wrong." 
Table 3

Comparison of the textbooks in different periods

\begin{tabular}{lcc}
\hline Period & No. of Textbooks & Mean Points $^{\mathrm{a}}$ \\
\hline $1966-89$ & 23 & 4.43 \\
$1990-99$ & 21 & 5.00 \\
$2000-02$ & 13 & 5.46 \\
All textbooks & 57 & 4.88 \\
\hline
\end{tabular}

${ }^{\mathrm{a}}$ All textbooks were evaluated (see Criteria section) on a scale of $0-14$ points. On each criterion, textbooks were awarded the following points: satisfactory $=2$ points; mention $=$ 1 point; no mention $=0$ point.

\section{Do Recent Textbooks Include More History and Philosophy of Science?}

Given the importance and recognition in recent years (Matthews, 1998) of the role played by history and philosophy of science (HPS) in science education, it would be of interest to examine whether new textbooks include more HPS details. Table 3 shows that, although the mean score (points) of the textbooks in the different periods increased from 1966 onward, the differences are not statistically significant ( $t$-test). It appears that more work needs to be done for the inclusion of HPS details in the presentation of the periodic table. Most textbooks lack a coherent, well-defined HPS framework based on heuristic principles.

\section{Conclusion and Educational Implications}

The historical reconstruction of the development of the periodic table shows that Mendeleev's (and others) ingenuity consisted in precisely recognizing that the periodic table was not only an inductive generalization, but, based on the atomic theory, there was also a reason/cause/ explanation of this periodicity.

Evaluation of the textbooks shows that almost all recognize the importance of accommodation of the elements according to their physicochemical properties (Criterion 1). The importance of contrapredictions (unknown elements) is recognized by about $75 \%$ of the textbooks (Criterion 2) and that of novel predictions (known elements) by about $40 \%$ of the textbooks (Criterion 4). In contrast, very few textbooks emphasize the relative importance of accommodation and prediction (Criterion 3). Few textbooks attempt to explore the possible causes of periodicity in the periodic table (Criterion 5). Very few textbooks explore the nature of Mendeleev's contribution, viz., ordered domain, empirical law, or a theory with a limited explanatory power (Criterion 6). Few textbooks make an attempt to present ("weave") the development of the periodic table as a sequence of heuristic principles in the form of a convincing argument (Criterion 7).

This study has the following educational implications that can help to improve the presentation of periodic table in general chemistry textbooks:

- Relative importance of accommodation of the elements according to their properties and prediction of new elements as evidence to support the periodic law constitute two facets of the scientific research methodology that can facilitate students' understanding of progress in science.

- The textbook approach of emphasizing that the development of the periodic table was an inductive generalization and that Mendeleev had no model or theory, does not facilitate the spirit of critical inquiry that led the scientists to grapple with alternative interpretations, conflicts, and controversies. Most textbooks explain the accommodation of the 
elements and periodicity due to electron configurations based on the modern atomic theory. Textbooks could foster thinking and curiosity with respect to a question that many students must have entertained: How could a simple arrangement of the elements based on atomic mass provide such regularities?

- Textbooks give the impression that for almost 100 years (1820-1920) scientists had no idea or never asked the question as to whether there could be an underlying pattern to explain periodicity? In other words, textbooks provide students a noncontroversial "finished product" that could explain periodicity and the nature of the periodic table only when the modern atomic theory was formulated. The textbook approach does not facilitate students' understanding with respect to the tentative nature of science, considered to be important by modern philosophers of science and also science educators.

- In contrast to the "Baconian inductive ascent" perspective of the textbooks, study of experimental properties of the elements was not an isolated process, but rather there was a constant preoccupation (conflict and controversy) to understand and explain the periodicity of physicochemical properties. It is plausible to suggest that development of the periodic table went through a continual critical appraisal, in which scientists presented various tentative theoretical ideas to understand the experimental properties of the elements.

- Discussion of the nature of Mendeleev's contribution can enhance students' appreciation with respect to alternative forms of conceptualizing progress in science. A critical review of the philosophy of science literature provides three alternatives with respect to the nature of Mendeleev's contribution: (a) ordered domain or codification scheme; (b) an empirical law; and (c) an "interpretative" theory, which became "explanatory" after the periodic law was based on atomic number (cf. Lakatos, 1970). Furthermore, neither science nor scientists can provide the final/true explanation.

- Development of the periodic table can be followed as a sequence of heuristic principles: Accumulation of data with respect to atomic weights $\rightarrow$ Early ideas about atomic theory $\rightarrow$ Attempts to classify elements starting in $1817 \rightarrow$ Mendeleev's first periodic table in $1869 \rightarrow$ Discovery of argon in $1895 \rightarrow$ Contribution of Moseley in 1913 and the periodic table based on atomic numbers. Other episodes from the history of the periodic table can be incorporated to "weave" a convincing story for students.

\section{References}

Akeroyd, F.M. (1991). Predictions and the nature of science. School Science Review, 72, $138-141$.

Akeroyd, F.M. (2003). Prediction and the periodic table: A response to Scerri and Worrall. Journal for General Philosophy of Science, 34, 337-355.

Ander, P. \& Sonessa, A.J. (1968). Principles of chemistry: An introduction to theoretical concepts. New York: Macmillan.

Anderson, C.B., Ford, P.C., \& Kennedy, J.H. (1973). Chemistry: Principles and applications. Lexington, MA: Heath.

Atkins, P. (1995). The periodic kingdom. A journey into the land of the chemical elements. New York: Harper Collins.

Atkins, P. \& Beran, J. (1992). General chemistry (2nd ed.). New York: Scientific American Books.

Atkins, P. \& Jones, L. (2002). Chemical principles: The quest for insight (2nd ed.) New York: Freeman.

Bensaude-Vincent, B. (1986). Mendeleev's periodic system of chemical elements. British Journal for the History of Science, 19, 3-17. 
Ben-Zvi, N. \& Genut, S. (1998). Uses and limitations of scientific models: The periodic table as an inductive tool. International Journal of Science Education, 20, 351-360.

Bishop, M. (2002). An introduction to chemistry. San Francisco: Benjamin Cummings.

Bodner, G.M. \& Pardue, H.L. (1989). Chemistry: An experimental science. New York: John Wiley \& Sons.

Bohr, N. (1913). On the constitution of atoms and molecules. Part II. Systems containing only a single nucleus. Philosophical Magazine, 26 (Series 6, No. 153), 476-502.

Bouma, J. (1989). An application-oriented periodic table of the elements. Journal of Chemical Education, 66, 741-745.

Brady, J.E. (2000). General chemistry. Principles and structures (2nd ed., Spanish). New York: John Wiley \& Sons.

Brady, J.E. \& Holum, J.R. (1981). Fundamentals of chemistry. New York: Wiley.

Brady, J.E. \& Humiston, G.E. (1996). General chemistry: Principles and structure (Spanish ed.). New York: John Wiley \& Sons.

Brady, J.E., Russell, J.W., \& Holum, J.R. (2000). Chemistry: Matter and its changes. New York: John Wiley \& Sons.

Brown, T.L., LeMay, H.E., \& Bursten, B.E. (1997). Chemistry: The central science (7th ed.) Englewood Cliffs, NJ: Prentice Hall.

Burbules, N.C. \& Linn, M.C. (1991). Science education and philosophy of science: Congruence or contradiction? International Journal of Science Education, 13, 227-241.

Brush, S.G. (1976). The kind of motion we call heat: A history of the kinetic theory of gases in the 19th century (Book 1). New York: North-Holland.

Brush, S. (1996). The reception of Mendeleev's periodic law in America and Britain. Isis, 87, $595-628$.

Burns, R.A. (1995). Fundamentals of chemistry (2nd ed., Spanish). Englewood Cliffs, NJ: Prentice Hall.

Campbell, J.A. (1989). Let us make the table periodic. Journal of Chemical Education, 66, 739-740.

Cartwright, N. (1983). How the laws of physics lie. Oxford, UK: Oxford University Press.

Chang, R. (1998). Chemistry (6th ed., Spanish). New York: McGraw-Hill. 306.

Crookes, W. (1877). The chemistry of the future. Quarterly Journal of Science, N.S., 7, 289-

Daub, G.W. \& Seese, W.S. (1996). Basic chemistry (7th ed., Spanish). Englewood Cliffs, NJ: Prentice Hall.

de Milt, C. (1951). The congress at Karlsruhe. Journal of Chemical Education, 28, 421425.

Dickerson, R.E., Gray, H.B., Darensbourg, M.Y., \& Darensbourg, D.J. (1984). Chemical principles (4th ed.) Menlo Park, CA: Benjamin Cummings.

Dickson, T.R. (2000). Introduction to chemistry (8th ed.) New York: John Wiley \& Sons.

Dillard, C.R. \& Goldberg, D.E. (1971). Chemistry: Reactions, structure and properties (Spanish ed.). New York: Macmillan.

Ebbing, D.D. (1996). General chemistry (5th ed., Spanish). New York: Houghton Mifflin.

Giere, R.N. (1995). The skeptical perspective: Science without laws of nature. In F. Weinert (Ed.), Laws of nature: Essays on the philosophical, scientific and historical dimensions (pp. 120138). Berlin: Walter de Gruyter.

Giere, R.N. (1999). Science without laws. Chicago: University of Chicago Press.

Giunta, C. (1998). Using history to teach scientific method: The case of argon. Journal of Chemical Education, 75, 1322-1325. 
Giunta, C. (2001). Argon and the periodic system: The piece that would not fit. Foundations of Chemistry, 3, 105-128.

Gavroglu, K. (2000). Controversies and the becoming of physical chemistry. In P. Machamer, M. Pera, \& A. Baltas (Eds.), Scientific controversies: Philosophical and historical perspectives (pp. 177-198). New York: Oxford University Press.

Goh, N.K. \& Chia, L.S. (1989). Using the learning cycle to introduce periodicity. Journal of Chemical Education, 66, 747-749.

Goldberg, D.E. (2001). Fundamentals of chemistry (3rd ed.) New York: McGraw-Hill.

Gray, H.B. \& Haight, G.P. (1983). Basic principles of chemistry (Spanish ed.). New York: Benjamin.

Heilbron, J. (1966). The work of H.G.J. Moseley. Isis, 57, 336-363.

Heilbron, J.L. \& Kuhn, T.S. (1969). The genesis of the Bohr atom. Historical Studies in the Physical Sciences, 1, 211-290.

Hein, M. \& Arena, S. (1997). Foundations of college chemistry (Spanish ed.). Pacific Grove, CA: Brooks/Cole.

Hill, J.W. \& Petrucci, R.H. (1999). General chemistry: An integrated approach (2nd ed.) Upper Saddle River, NJ: Prentice-Hall.

Holton, G. (1992). Ernst Mach and the fortunes of positivism in America. Isis, 83, 27-60.

Holtzclaw, H.F. \& Robinson, W.R. (1988). General chemistry (8th ed.) Lexington, MA: Heath.

Ihde, A.J. (1969). Foreword. In J.W. van Spronsen (Ed.), The periodic system of chemical elements: A history of the first hundred years. Amsterdam: Elsevier.

Joesten, M.D., Johnston, D.O., Netterville, J.T., \& Wood, J.L. (1991). World of chemistry. Philadelphia: Saunders.

Jones, L. \& Atkins, P. (2000). Chemistry: Molecules, matter, and change (4th ed.) New York: Freeman.

Kaji, M. (2003). Mendeleev's discovery of the periodic law: The origin and the reception. Foundations of Chemistry, 5, 189-214.

Knight, D. (1998). Preface. In D. Knight \& H. Kragh (Eds.), The making of the chemist: The social history of chemistry in Europe, 1789-1914. Cambridge, UK: Cambridge University Press.

Kotz, J.C. \& Purcell, K.F. (1991). Chemistry and chemical reactivity (2nd ed.) Philadelphia: Saunders.

Kragh, H. (2000). Conceptual changes in chemistry: The notion of a chemical element, ca. 1900-1925. Studies in History and Philosophy of Science, 31B, 435-450.

Ladenburg, R. (1920). Atombau und periodisches system der elemente. Zeitschrift für Elektrochemie, 26, 262-274.

Lakatos, I. (1970). Falsification and the methodology of scientific research programmes. In I. Lakatos \& A. Musgrave (Eds.), Criticism and the growth of knowledge (pp. 91-195). Cambridge, UK: Cambridge University Press.

Laing, M. (1989). The periodic table-A new arrangement. Journal of Chemical Education, $66,746$.

Lewis, G. (1923). Valence and the structure of atoms and molecules. New York: Chemical Catalog Co.

Lippincott, W.T., Garrett, A.B., \& Verhoek, F.H. (1977). Chemistry: A study of matter (3rd ed.) New York: John Wiley \& Sons.

Lipton, P. (1991). Inference to the best explanation. London: Routledge.

Mahan, B. \& Myers, R.J. (1987). University chemistry (4th ed., Spanish). Menlo Park, CA: Benjamin Cummings. 
Maher, P. (1988). Prediction accommodation and the logic of discovery. In A. Fine \& J. Leplin (Eds.), PSA 1988. Vol. 1. East Lansing, MI: Philosophy of Science Association.

Malone, L.J. (2001). Basic concepts of chemistry (6th ed.) New York: John Wiley \& Sons.

Marshall, J.L. (2000). A living periodic table. Journal of Chemical Education, 77, 979-983.

Masterton, W.L. \& Hurley, C.N. (1993). Chemistry. Principles and reactions (2nd ed.) Philadelphia: Saunders.

Masterton, W.L., Slowinski, E.J., \& Stanitski, C.L. (1985). Chemical principles (6th ed.) New York: McGraw-Hill.

Matthews, M.R. (1998). In defense of modest goals when teaching about the nature of science. Journal of Research in Science Teaching, 35, 161-174.

McComas, W.F., Almazroa, H., \& Clough, M.P. (1998). The nature of science in science education: An introduction. Science and Education, 7, 511-532.

McMurry, J. \& Fay, R.C. (2001). Chemistry (3rd ed.) Upper Saddle River, NJ: Prentice Hall.

Mendeleev, D. (1869). Ueber die beziehungen der eigenschaften zu den atom gewichten der elemente. Zeitschrift für Chemie, 12, 405-406 (English trans. by C. Giunta).

Mendeleev, D. (1879). The periodic law of the chemical elements. The Chemical News, 40, No. 1042.

Mendeleev, D. (1889). The periodic law of the chemical elements (Faraday lecture, delivered on 4 June 1889). Journal of the Chemical Society, 55, 634-656.

Mendeleev, D. (1897). The principles of chemistry (2nd English ed., trans. of sixth Russian ed.). New York: American Home Library Co.

Miller, G.H. (1969). Chemistry. New York: Harper \& Row.

Moore, J.W., Stanitski, C.L., \& Jurs, P.C. (2002). Chemistry: The molecular science. Orlando, FL: Harcourt College.

Mortimer, C.E. (1983). Chemistry (5th ed.) Belmont, CA: Wadsworth.

Moseley, H.G.J. (1913). High frequency spectra of the elements. Philosophical Magazine, 26, $1025-1034$.

Moseley, H.G.J. (1914). High frequency spectra of the elements. Part II. Philosophical Magazine, 27, 703-713.

Newell, S.B. (1977). Chemistry: An introduction. Boston: Little, Brown \& Co.

Niaz, M. (2001). Understanding nature of science as progressive transitions in heuristic principles. Science Education, 85, 684-690.

O'Connor, R. (1974). Fundamentals of chemistry (Spanish ed.). New York: Harper \& Row.

Oxtoby, D.W., Nachtrieb, N.H., \& Freeman, W.A. (1994). Chemistry: Science of change (2nd ed.) Philadelphia: Saunders.

Partington, J.R. (1948). A short history of chemistry (2nd ed.) London: Macmillan.

Petrucci, R.H. (1989). General chemistry: Principles and modern applications (5th ed.) New York: Macmillan.

Petrucci, R.H. \& Harwood, W. (1997). General chemistry: Principles and modern applications (7th ed.) Englewood Cliffs, NJ: Prentice-Hall.

Phillips, J.S., Strozak, V.S., \& Wistrom, C. (2000). Chemistry: Concepts and applications (Spanish ed.) New York: McGraw-Hill.

Quagliano, J.V. \& Vallarino, L.M. (1969). Chemistry (3rd ed.) Englewood Cliffs, NJ: Prentice-Hall.

Ramsey, W. (1897). An undiscovered gas (address to the Section of Chemical Science of the British Association). Nature, 56, 378-382.

Ramsey, W. \& Travers, M.W. (1901). Philosophical Transactions of the Royal Society A, 197, 47. 
Rayner-Canham, G. (2000). Periodic patterns. Journal of Chemical Education, 77, 10531056.

Reger, D.L., Goode, S.R., \& Mercer, E.E. (1997). Chemistry: Principles and practice (2nd ed.) Philadelphia: Saunders.

Robinson, J. (2000). The paradigm changes-But do our students know that? Journal of College Science Teaching, 29, 177-182.

Rucker, W.A. \& Lord Kelvin. (1985). Contribution to 'Untitled comments.' Chemical News, 71(1836):62.

Russo, S. \& Silver, M. (2002). Introductory chemistry (2nd ed.) San Francisco: Benjamin Cummings.

Rutherford, E. (1911). The scattering of alpha and beta particles by matter and the structure of the atom. Philosophical Magazine, 21, 669-688.

Rutherford, E. (1915). The constitution of matter and the evolution of the elements. Address to the annual meeting of the National Academy of Sciences (pp. 167-202). Washington, DC: Smithsonian Institution.

Scerri, E. (1998). How good is the quantum mechanical explanation of the periodic table? Journal of Chemical Education, 75, 1384-1385.

Scerri, E.R. \& Worrall, J. (2001). Prediction and the periodic table. Studies in History and Philosophy of Science, 32, 407-452.

Schmidt, H.-J., Baumgärtner, T., \& Eybe, H. (2003). Changing ideas about the periodic table of elements and students' alternative concepts of isotopes and allotropes. Journal of Research in Science Teaching, 40, 257-277. Sons.

Segal, B.G. (1989). Chemistry: Experiment and theory (2nd ed.) New York: John Wiley \&

Shapere, D. (1977). Scientific theories and their domains. In F. Suppe (Ed.). The structure of scientific theories (2nd ed., pp. 518-565). Chicago: University of Illinois Press.

Sienko, M.J. \& Plane, R.A. (1971). Chemistry (4th ed.) New York: McGraw-Hill.

Silberberg, M.S. (2000). Chemistry: The molecular nature of matter and change (2nd ed.) New York: McGraw-Hill.

Sisler, H.H., Dresdner, R.D., \& Mooney, W.T. (1980). Chemistry: A systematic approach. New York: Oxford University Press.

Slabaugh, W.H. \& Parsons, T.D. (1966). General chemistry (Spanish ed.). New York: John Wiley \& Sons.

Smith, J.R. (1975). Persistence and periodicity. Unpublished PhD thesis, University of London.

Spencer, J.N., Bodner, G.M., \& Rickard, L.H. (1999). Chemistry: Structure and dynamics. New York: John Wiley \& Sons.

Stoker, H.S. (1990). Introduction to chemical principles (3rd ed.) New York: Macmillan.

Thomson, J.J. (1897). Cathode rays. Philosophical Magazine, 44, 293-316.

Thomson, J.J. (1904). On the structure of the atom. Philosophical Magazine, 7(Series 6), No. 39, 237-265.

Treptow, R.S. (1994). The periodic table of atoms: Arranging the elements by a different set of rules. Journal of Chemical Education, 71, 1007-1012.

Umland, J. (1993). General chemistry. St. Paul, MN: West Publishing Co.

Umland, J.B. \& Bellama, J.M. (1999). General chemistry (3rd ed.) Pacific Grove, CA: Brooks/Cole.

van Spronsen, J. (1959). The prehistory of the periodic system of the elements. Journal of Chemical Education, 36, 565-567. 
van Spronsen, J. (1969). The periodic system of chemical elements. A history of the first hundred years. Amsterdam: Elsevier.

Wartofsky, M.W. (1968). Conceptual foundations of scientific thought: An introduction to the philosophy of science. New York: Macmillan.

Whitten, K.W., Davis, R.E., \& Peck, M.L. (1996). General chemistry (5th ed., Spanish). Philadelphia: Saunders.

Wolfe, D.H. (1988). Introduction to college chemistry (2nd ed.) New York: McGraw-Hill.

Wood, J.H., Keenan, C.W., \& Bull, W.E. (1968). Fundamentals of college chemistry (Spanish ed.). New York: Harper \& Row.

Ziman, J. (1978). Reliable knowledge. An exploration of the grounds for belief in science. Cambridge, UK: Cambridge University Press.

Zumdahl, S.S. (1993). Chemistry (3rd ed.) Lexington, MA: Heath. 